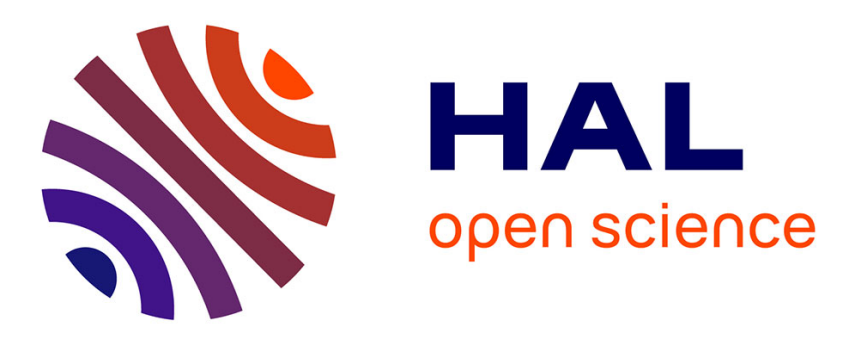

\title{
Implementing varying blade profile and Reynolds Number in BEMT code
}

Iestyn Evans, Michael Togneri, Thomas Lake, R. Gwenter, Ian Masters, Grégory Pinon, Myriam Slama

\section{- To cite this version:}

Iestyn Evans, Michael Togneri, Thomas Lake, R. Gwenter, Ian Masters, et al.. Implementing varying blade profile and Reynolds Number in BEMT code. Developments in Renewable Energies Offshore (1st ed.),, 2020. hal-03456501

\section{HAL Id: hal-03456501 \\ https://hal-normandie-univ.archives-ouvertes.fr/hal-03456501}

Submitted on 30 Nov 2021

HAL is a multi-disciplinary open access archive for the deposit and dissemination of scientific research documents, whether they are published or not. The documents may come from teaching and research institutions in France or abroad, or from public or private research centers.
L'archive ouverte pluridisciplinaire HAL, est destinée au dépôt et à la diffusion de documents scientifiques de niveau recherche, publiés ou non, émanant des établissements d'enseignement et de recherche français ou étrangers, des laboratoires publics ou privés. 


\title{
Implementing varying blade profile and Reynolds Number in BEMT code
}

\author{
I.Evans, M.Togneri, T.Lake, R.Gwenter \& I.Masters \\ Marine Energy Research Group \\ Swansea University, Wales \\ G.Pinon \& M.Slama \\ Laboratory of Waves and Complex Media \\ University of Normandy, France
}

\begin{abstract}
Cost, driven mostly by planned and unplanned maintenance, is the most significant barrier limiting widespread adoption of TECs. Accurate numerical models can be used to predict the structural loads on TECs and help improve their reliability. BEMT offers an efficient method for predicting the performance of TECs. A robust but unoptimized BEMT code, implemented in MATLAB, has been developed at Swansea University. Previous versions of the BEMT code only allowed for inputs of constant blade profile and Reynolds Number which contributed to the inaccuracies of the BEMT model in predicting experimental results. We present a faster and more accurate $\mathrm{C}++$ implementation of the BEMT code. The error between the coefficient of power from the BEMT code and results of laboratory testing at optimum TSR was reduced by $13 \%$. This should in turn improve the design of TEC, reducing their cost and increase their adoption as generators of low carbon energy.
\end{abstract}

\section{INTRODUCTION}

Tidal Stream Turbines (TST) have the potential to become significant contributors of clean renewable energy, reducing our dependency on fossil fuels (Melikoglu 2018, Pelc and Fujita 2002). Generating energy form the tide has a distinct advantage of being very predictable, compared to other renewable energy sources such as wind, solar or wave (Pelc and Fujita 2002). Estimations of potential tidal energy in the United Kingdom is 50.2-95TWh/yr, 105.4TWh/yr in Western Europe, and 500-1000TWh/yr worldwide (Melikoglu 2018, Pelc and Fujita 2002). A significant barrier for TST is the expense of operations at sea; more specifically the expense of planned and unplanned maintenance (Johnstone et al. 2013, Astariz et al. 2015, Sagar and Van Der Zwaan 2006). Improving the design of TST to minimise the number of planned and unplanned maintenance will greatly increase their popularity.

Blade Element Momentum Theory (BEMT) is a common tool used in the design and performance evaluation of TST. A robust BEMT model has been developed at Swansea University (Masters et al. 2011, Chapman et al. 2013), which will be the foundation of this work. Previous versions of the BEMT code only allowed for inputs of constant blade profile and Reynolds Number across the radius of the blade. No rotor has a constant blade profile and Reynolds Number across its radius which leads to in-accuracies in the results when using the BEMT model. Implementing inputs of varying blade profile and Reynolds Number across the radius of the blade in the BEMT model will increase the accuracy of the of the blade and hence the results. The BEMT code is also translated and implemented in $\mathrm{C}++$ which should give significant performance gains.

Improvements in the accuracy and performance of the BEMT model will directly enhance the design and evaluation of TST. A reduction in cost of TST will be seen with a better design which is achievable from the more accurate BEMT model. This will increase the popularity of TST as generators of clean renewable energy.

\section{BLADE ELEMENT MOMENTUM THEORY}

BEMT is a common numerical model that is available for predicting the performance of TST (OrdonezSanchez et al. 2019). It was originally developed in the late $19^{\text {th }}$ century for marine and aviation propellers, before being applied to wind turbines and later tidal turbines (Burton et al. 2001, Houghton and Brock 1960). BEMT is often the preferred numeri- 


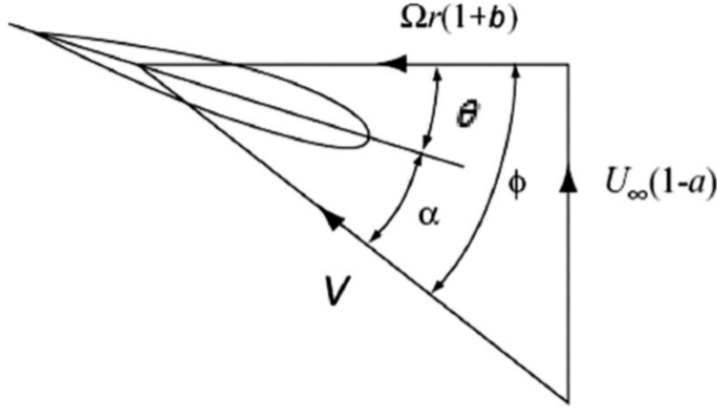

(a) Velocities

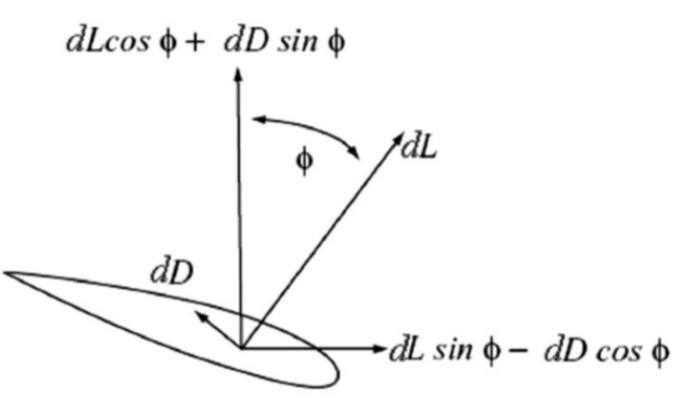

(b) Forces

Figure 1: Blade element velocities and forces.

cal model for predicting the performance of TST as it offers acceptable accuracy for evaluation at low computational cost (Masters et al. 2011, Batten et al. 2007, Mannion et al. 2020). In a computationally efficient manner, the BEMT model calculates the performance of a turbine by combining two methods; the momentum "actuator disk" theory and the blade element theory (Burton et al. 2001, Hansen 2008). The following is a brief description of the BEMT model as detailed description are commonly available (Burton et al. 2001, Hansen 2008).

The momentum theory assumes a stream-tube with an frictionless permeable actuator disk that represents the rotor as shown in Figure 2. It is assumed that the actuator disk does not interact with fluid outside of the stream-tube. Energy is removed from the stream-tube by drag force produced by the actuator disk.

There are two parts to the momentum theory; linear and rotational theories which differentiate by the assumption of the interaction of the actuator disk and the flow. In linear momentum theory the actuator disk is assumed to incur no rotational velocity to the flow whilst in the rotational momentum theory the actuator disk is assumed to incur rotation to the flow. Bernoulli's equation is used as the foundations in deriving equations for axial force and torque for the rotor blade. Two important factors are introduced; the axial induction factor (1), $a$, and the tangential induction factor (2), $b$. The axial induction factor, $a$, repre-

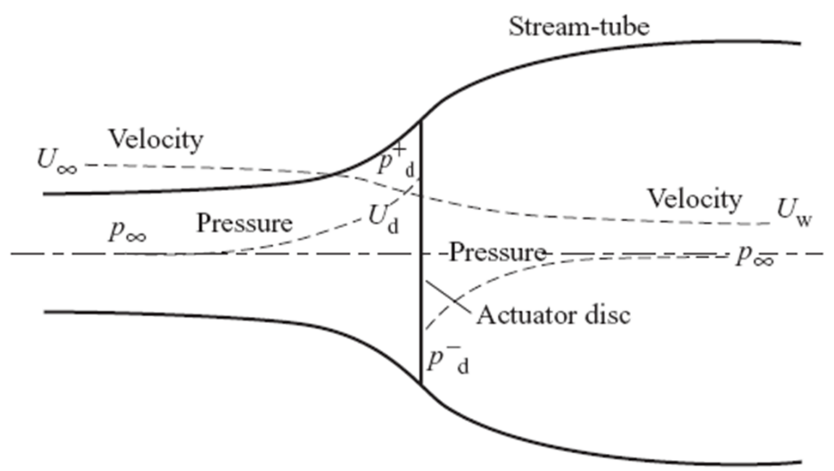

Figure 2: Energy extracting actuator disk and stream-tube. sents the fractional reduction in flow speed from far upstream, $U_{\infty}$, to the flow speed at the actuator disk, $U_{D}$, whilst the tangential induction factor, $b$, represents the change in tangential velocity of the flow before and after the actuator disk.

$$
\begin{aligned}
& a=1-\frac{U_{\mathrm{D}}}{U_{\infty}} \\
& b=\frac{\omega}{2 \Omega}
\end{aligned}
$$

where $\omega$ is the increase in tangential velocity and $\Omega$ is the tangential speed of the rotor (control volume).

The blade element theory divides the rotor blade into two-dimensional elements along its length. There is no fluid interaction between the elements and thus the loads on the blades can be assumed to rely solely on the lift and drag characteristics of the blade shape. Figure 1 is a diagram showing velocities and forces for a blade element at radius $r$ relative to the blade chord line. $\theta, \alpha$, and $\phi$ represent combined pitch and twist of the blade, angle of attack of the blade from the resultant flow, and inclination of the resultant flow respectively. $d L$ and $d D$ are the element lift and drag forces respectively whilst $V$ is the resultant flow. Axial force and torque for the rotor blade are found by resolving the lift and drag forces.

Two formulae for element axial force and torque now exist, derived from two theories. These equations are combined into a single minimisation function and solved (Masters et al. 2011). Once the minimisation function is solved, the remaining performance characteristics of the rotor are straightforward to calculate.

\section{METHODOLOGY}

\subsection{Blade Profile Description}

A comparison between the BEMT model and experimental results will be made to quantify any improvements in the accuracy of the BEMT model. The rotor blade used for comparison between the experimental and BEMT model will be the Magallanes ATIR 


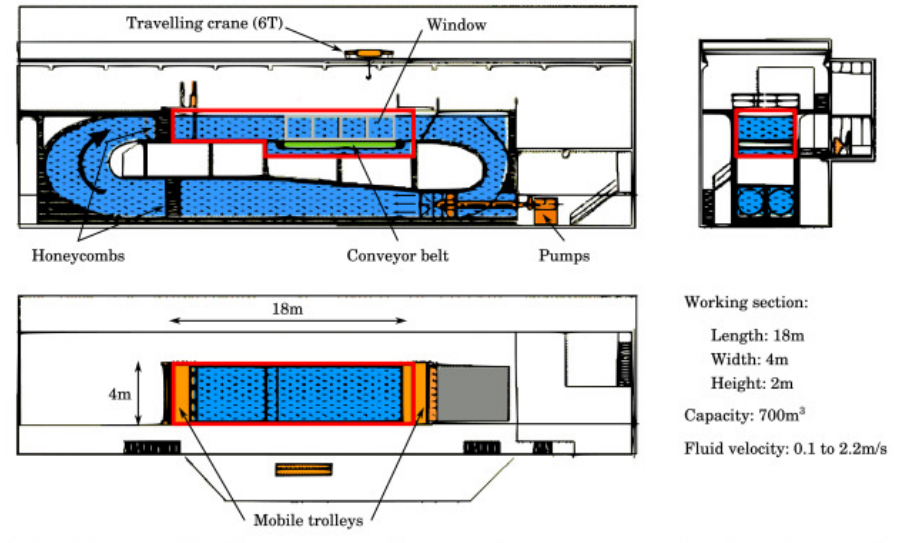

Figure 3: Schematic of the IFREMER wave and current flume tank.

turbine (Mycek et al. 2014). A detailed blade profile description of the ATIR turbine is shown in Table 1 (Mycek et al. 2014). As is clearly seen in Table 1 the ATIR turbine blade geometry, and thus lift and drag characteristics, changes significantly from its root to tip. For the BEMT model to accurately predict the performance of the rotor blade it must account for its varying blade profile.

Table 1: Detailed ATIR blade profile description.

\begin{tabular}{llll}
\hline $\mathrm{r} / \mathrm{R}$ & $\mathrm{c} / \mathrm{R}$ & Pitch $(\mathrm{deg})$ & $\mathrm{t} / \mathrm{c}(\%)$ \\
\hline 0.1333 & 0.0567 & 29.5672 & 80.0 \\
0.1500 & 0.0567 & 29.5672 & 100.0 \\
0.1550 & 0.0567 & 29.5672 & 100.0 \\
0.1983 & 0.1521 & 25.6273 & 36.0 \\
0.2417 & 0.2474 & 22.1491 & 21.3 \\
0.2850 & 0.2375 & 19.3031 & 21.4 \\
0.3283 & 0.2259 & 16.9737 & 21.7 \\
0.3717 & 0.2141 & 15.0538 & 22.0 \\
0.4150 & 0.2029 & 13.4572 & 22.2 \\
0.4583 & 0.1925 & 12.1169 & 22.4 \\
0.5017 & 0.1829 & 10.9815 & 22.5 \\
0.5450 & 0.1743 & 10.0114 & 22.5 \\
0.5883 & 0.1665 & 9.1761 & 22.4 \\
0.6317 & 0.1594 & 8.4516 & 22.2 \\
0.6750 & 0.1529 & 7.8191 & 21.9 \\
0.7183 & 0.1471 & 7.2638 & 21.5 \\
0.7617 & 0.1418 & 6.7735 & 20.9 \\
0.8050 & 0.1370 & 6.3387 & 20.2 \\
0.8483 & 0.1325 & 5.9514 & 19.5 \\
0.8917 & 0.1285 & 5.6050 & 18.6 \\
0.9350 & 0.1247 & 5.2941 & 18.0 \\
0.9783 & 0.1213 & 5.0143 & 18.0 \\
1.0000 & 0.0655 & 4.8743 & 25.0 \\
\hline
\end{tabular}

\subsection{Experimental Procedure}

The experimental testing was carried out by University Le Havre Normandy, France at IFREMER wave and current flume tank in Boulogne-Sur-Mer, France. Detailed description of the IFREMER wave and current flume tank can be found in previous works (Gaurier et al. 2020, Blackmore et al. 2016, Maganga et al. 2010, Medina et al. 2017, Mycek et al. 2014). A schematic of the IFREMER wave and current flume tank is shown in Figure 3 (Gaurier et al. 2020).
The ATIR turbine used in the experimental testing had 3 blades with profiles based on the NACA 63418 aerofoil with a radius of $0.338 \mathrm{~m}$. It was tested at flow speeds between $0.8-1.4 \mathrm{~m} / \mathrm{s}$, in Reynolds Number range of [2.7-4.7] $\times 10^{5}$, and in the tip speed ratio (TSR) range of 0-8.

\subsection{BEMT procedure}

The robust BEMT model developed at Swansea University that is implemented in MATLAB will be translated to $\mathrm{C}++$. Implementation of the BEMT model in $\mathrm{C}++$ should achieve a significant increase in performance. The BEMT model in $\mathrm{C}++$ will allow inputs of varying blade profile and Reynolds Number across the radius of the rotor. Comparison of results from the BEMT model with inputs of constant and varying blade profile and Reynolds Number will be made against experimental data. Plots of coefficients of power against TSR will be used for comparison. The BEMT model will match all of the experimental key parameters, such as flow speed, turbulence intensity (TI), Reynolds Number, etc.. The rotor blade used in the BEMT model will have 12 elements. A detailed description of the 12 elements used in the BEMT model are given in Table 2. Figure 4 shows the blade profile of the 12 elements. Each element will be assigned unique lift and drag coefficients depending on its profile and Reynolds Number.

Reynolds Number for each element is calculated by using equation (3), where $V$ is the velocity of the fluid with respect to the rotor $(\mathrm{m} / \mathrm{s}), L$ is the characteristic linear dimension, i.e half the chord length $(\mathrm{m})$, and $\nu$ which is the kinematic viscosity $\left(\mathrm{m}^{2} / \mathrm{s}\right)$. $V$ is calculated using equation (4), where $U$ is the free stream velocity of the fluid $(\mathrm{m} / \mathrm{s}), \boldsymbol{\omega}$ is the rotational speed of the blade $(\mathrm{Hz})$, and $r$ is the blade length $(\mathrm{m})$. The Reynolds Number for each element will be calculated at the rotors optimum rotational speed, which is around $18.5 \mathrm{~Hz}$.

$$
\begin{aligned}
& R e=\frac{V L}{\nu} \\
& V=\sqrt{U^{2}+(\omega r)^{2}}
\end{aligned}
$$

Table 2: Detailed description of the 12 elements used in the BEMT model.

\begin{tabular}{lllll}
\hline Element & $\mathrm{r} / \mathrm{R}$ & $\mathrm{c} / \mathrm{R}$ & Pitch $(\mathrm{deg})$ & $\mathrm{t} / \mathrm{c}(\%)$ \\
\hline 1 & 0.1263 & 0.1368 & 20.0 & 100 \\
2 & 0.1579 & 0.1368 & 20.0 & 100 \\
3 & 0.1789 & 0.1368 & 20.0 & 100 \\
4 & 0.2316 & 0.2444 & 17.9 & 43.1 \\
5 & 0.3368 & 0.2048 & 12.5 & 35.4 \\
6 & 0.4421 & 0.1845 & 10.5 & 30.7 \\
7 & 0.5474 & 0.1583 & 8.6 & 28.0 \\
8 & 0.6526 & 0.1270 & 7.1 & 27.8 \\
9 & 0.7579 & 0.0982 & 6.0 & 26.8 \\
10 & 0.8632 & 0.0759 & 5.2 & 24.3 \\
11 & 0.9158 & 0.0659 & 4.7 & 22.2 \\
12 & 1.0000 & 0.0543 & 4.3 & 17.4 \\
\hline
\end{tabular}




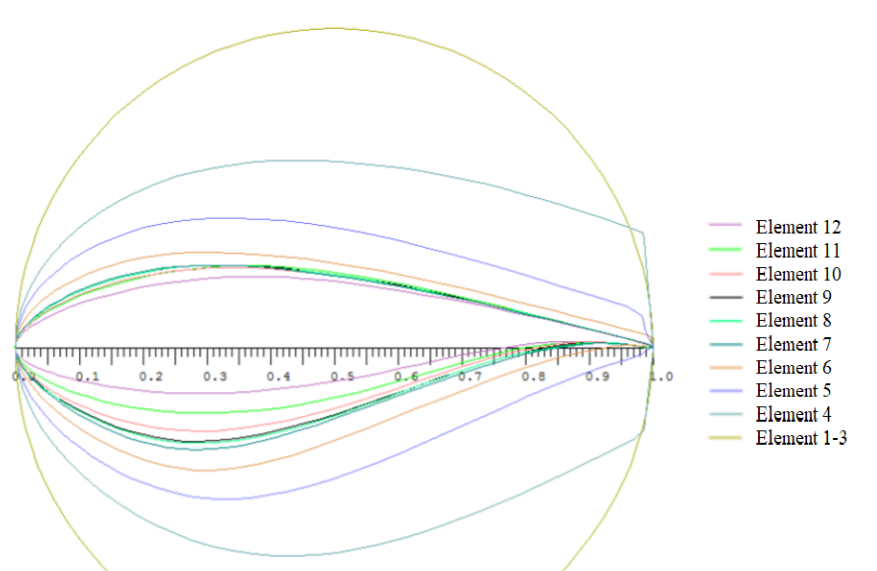

Figure 4: Blade profile of the 12 elements used in the BEMT model.

As previously discussed, the BEMT model divides the rotor blade into elements to calculate its performance from lift and drag characteristics. The Reynolds Number, and hence the lift and drag characteristics across the length of the rotor blade are commonly assumed to be constant, but this assumption is clearly inaccurate as seen in equations (3) and (4). Elemental blade length increases as you move along the blade from its hub to its tip, increasing the velocity of fluid with respect to the rotor, $V$.

After the calculation of Reynolds Number at each element the corresponding lift and drag coefficients are assigned. The lift and drag coefficients are interpolated from a two-dimensional blade profile and Reynolds Number table. A schematic of this interpolation table is shown in Figure 5, where (-) represents the lift and drag data. A linear correlation exists between the blade profile, Reynolds Number, and lift and drag coefficients which make interpolation relatively simple.

The lift and drag coefficients that populate the interpolation table will predominantly produced by computational fluid dynamic (CFD) simulations with the rest extrapolated from experimental testing. The CFD simulations will use the forceCoeffs function which is available from OpenFOAM. The forceCoeffs function generates aerodynamic force and moment coefficients data for surfaces and porous regions.

The constant blade profile BEMT model will use

\begin{tabular}{|c|c|c|c|c|c|c|c|}
\hline & & \multicolumn{6}{|c|}{ Blade Profile (e.g \% thickness/chord) } \\
\hline \multirow{7}{*}{$\begin{array}{l}\stackrel{20}{0} \\
\stackrel{0}{x} \\
\stackrel{0}{=}\end{array}$} & & 100 & 45 & 30 & 27 & 24 & 20 \\
\hline & 6 & - & - & - & - & - & - \\
\hline & 5 & - & - & - & - & - & - \\
\hline & 4 & - & - & - & - & - & - \\
\hline & 3 & - & - & - & - & - & - \\
\hline & 2 & - & - & - & - & - & - \\
\hline & 1 & - & - & - & - & - & - \\
\hline
\end{tabular}

Figure 5: Representation of interpolation table for lift and drag coefficients from blade profile and Reynolds Number. the lift and drag coefficients of element 6 , as this is the centre element and best represents the whole rotor blade.

\section{RESULTS}

The robust BEMT code from Swansea University has been translated from MATLAB to $\mathrm{C}++$. The robustness of the BEMT code in $\mathrm{C}++$ is tested by running a variety of know cases and checking the results against that of the MATLAB version. Results for all cases were the same for the $\mathrm{C}++$ and MATLAB version of the BEMT code, concluding that it has been correctly translated. The computational time of the BEMT code running in $\mathrm{C}++$ compared to MATLAB varied between different cases, but on average a reduction in the region of 100x was seen.

The following results are from the ATIR rotor in flow speed of $1.0 \mathrm{~m} / \mathrm{s}$ and TI of $1.3 \%$. Firstly, the Reynolds Number is calculated for each element from the given conditions. A graphical representation of Reynolds Number against blade length is shown in Figure 6. As predicted the Reynolds Number varies significantly from a minimum of 45,000 to a maximum of 145,000 across the the rotor blade. The interesting result is that the Reynolds Number decreases from the midpoint to the tip of the blade. It was expected that the Reynolds Number would continue to increase towards the blade tip due to the velocity of the fluid with respect to the blade also increasing towards the blade tip. The decreasing Reynolds Number is due to the chord length of the blade decreasing towards the tip.

Lift and drag coefficients are now assigned to each element based on their profile and Reynolds Number. Figure 7 shows lift coefficient against angle of attack between $-10^{\circ}$ and $20^{\circ}$ for each element. It is clearly seen that the lift coefficient for each element increases with the length of the rotor from the hub to the tip. The three elements closest to the hub have circular profile, producing no lift. Element 4 and 12 have maximum

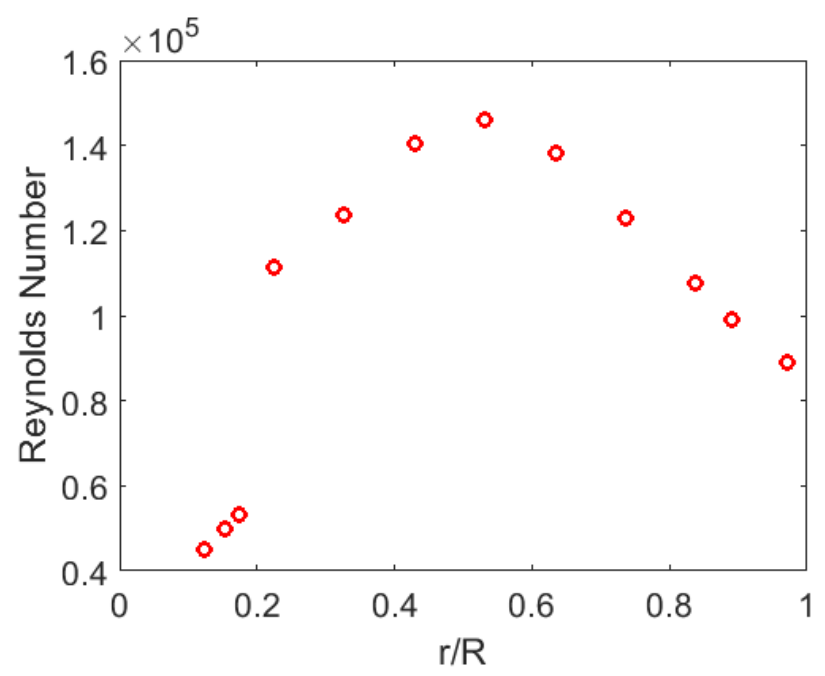

Figure 6: Reynolds Number across the ATIR blade length at flow speed of $1.0 \mathrm{~m} / \mathrm{s}$ at optimum rotational speed of $18.5 \mathrm{~Hz}$. 


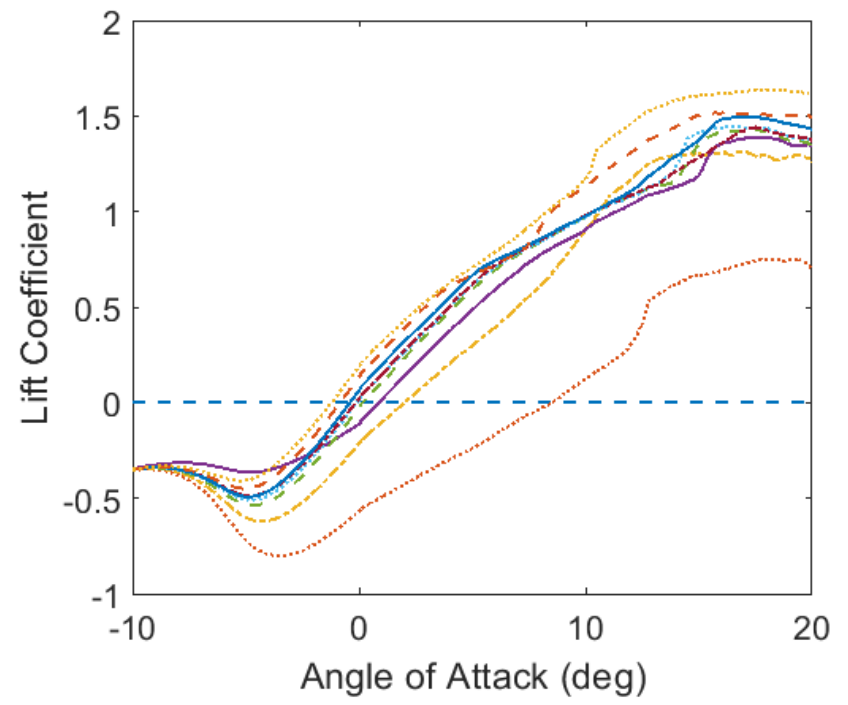

\begin{tabular}{|c|c|c|}
\hline - - - Element 1-3 & - - - Element 7 & - - - Element 11 \\
\hline ............ Element 4 & …….... Element 8 & Element 12 \\
\hline -Element 5 & -----Element 9 & \\
\hline -Element 6 & -Element 10 & \\
\hline
\end{tabular}

Figure 7: Lift coefficients for different elements between angle of attack $-10^{\circ}$ and $20^{\circ}$.

lift coefficients of 0.75 and 1.65 respectively. This is a significant difference which would cause inaccuracies in the BEMT rotor performance predictions if a constant lift coefficient was used across the whole rotor blade. The change in drag coefficients across all elements is smaller than the change in lift coefficients.

Comparison of coefficient of power (Cp) against tip speed ratio (TSR) from the varying blade profile BEMT model, constant blade profile BEMT model, and experimental laboratory test is shown in Figure 8. For reasons of commercial sensitivity, all $\mathrm{Cp}$ values have been anonymised by scaling with the maximum value of $\mathrm{Cp}$. The inclusion of varying blade profile in the BEMT model reduced the maximum coefficient of power by $13 \%$ to exactly match the maximum coefficient of power seen in the experimental result. It also reduced the TSR at maximum coefficient of power by $10 \%$ to better match that seen in the experimental result. The shape of the whole power coefficient against TSR curve for the varying blade profile BEMT model also better represents the curve seen from the experimental results. A closer representation of the experimental curve in over rotation condition, i.e TSR above 5 , is seen in the BEMT model with varying blade profile.

\section{CONCLUSIONS}

The translation and implementation of Swansea University robust BEMT model in $\mathrm{C}++$ from MATLAB resulted in run time reduction of 100x. The speed up of the BEMT model will allow for significantly more cases to be run, but also more complex cases that were

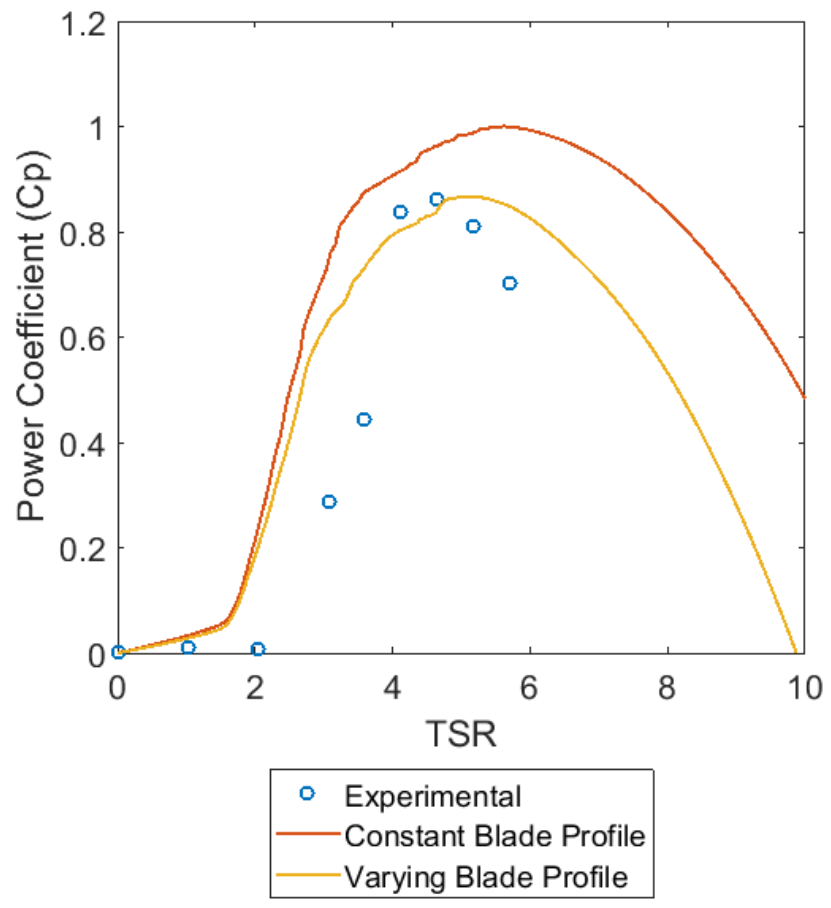

Figure 8: Comparison of coefficient of power against tip speed ratio for experimental and BEMT results.

not feasible to model in the MATLAB version. This should increase the speed and accuracy of tidal stream turbine design evaluation.

The inclusion of varying blade profile in the BEMT model significantly improves the results to the experimental data. This is achieved by assigning accurate lift and drag coefficients to each rotor blade element that matches the physical reality. The majority of rotor blade elements in the previous BEMT model were assigned incorrect lift and drag coefficients which often resulted in over predicting the performance of tidal stream turbines. Increasing the accuracy of the BEMT model in predicting the performance of tidal stream turbine will result in better design, reducing cost, and increase their adoption as generators of low carbon energy.

\section{REFERENCES}

Astariz, S., A. Vazques, \& G. Iglesias (2015). Evaluation and comparison of the levelized cost of tidal, wave and offshore wind energy. Journal of Renewable Sustainable Energy 7(5).

Batten, W., A. Bahaj, A. Molland, \& J. Chaplin (2007, may). Experimentally validated numerical method for the hydrodynamic design of horizontal axis tidal turbines. Ocean Engineering 34(7), 1013-1020.

Blackmore, T., L. Myers, \& A. Bahaj (2016). Effects of turbulence on tidal turbines: Implications to performance, blade loads, and condition monitoring. International Journal of Marine Energy 14, 1-26.

Burton, T., D. Sharpe, N. Jenkins, \& E. Bossanyi (2001). Wind energy handbook. Chichester.

Chapman, J., I. Masters, M. Togneri, \& J. Orme (2013, dec). The Buhl correction factor applied to high induction conditions for tidal stream turbines. Renewable Energy 60, 472-480. 
Gaurier, B., C. Carlier, G. Germain, G. Pinon, \& E. Rivoalen (2020, apr). Three tidal turbines in interaction: An experimental study of turbulence intensity effects on wakes and turbine performance. Renewable Energy 148, 1150-1164.

Hansen, M. (2008). Aerodynamics of wind turbines (2 ed.). London: Earthscan.

Houghton, E. \& A. Brock (1960). Aerodynamics for engineering students. Arnold.

Johnstone, C., D. Pratt, J. Clarke, \& A. Grant (2013). A technoeconomic analysis of tidal energy technology. Renew Energy 49, 101-106.

Maganga, F., G. Germain, J. King, G. Pinon, \& E. Rivoalen (2010). Experimental characterisation of flow effects on marine current turbine behaviour and on its wake properties. IET Renewable Power Generation 4(6), 314-327.

Mannion, B., S. B. Leen, \& S. Nash (2020, feb). Development and assessment of a blade element momentum theory model for high solidity vertical axis tidal turbines. Ocean Engineering 197, 106918.

Masters, I., J. C. Chapman, M. R. Willis, \& J. A. Orme (2011). A robust blade element momentum theory model for tidal stream turbines including tip and hub loss corrections. Journal of Marine Engineering and Technology 10(1), 25-35.

Medina, O., F. Schmitt, R. Calif, G. Germain, \& B. Gaurier (2017). Turbulence analysis and multiscale correlations between synchronized flow velocity and marine turbine power production. Renewable Energy 112, 314-327.

Melikoglu, M. (2018, jan). Current status and future of ocean energy sources: A global review. Ocean Engineering 148, 563-573.

Mycek, P., B. Gaurier, G. Germain, G. Pinon, \& E. Rivoalen (2014). Experimental study of the turbulence intensity effects on marine current turbines behaviour. Part 1: One single turbine. Journal of Renewable Energy 66, 729-746.

Ordonez-Sanchez, S., R. Ellis, K. Porter, M. Allmark, T. O’Doherty, A. Mason-Jones, \& C. Johnstone (2019, jun). Numerical models to predict the performance of tidal stream turbines working under off-design conditions. Ocean Engineering 181, 198-211.

Pelc, R. \& R. M. Fujita (2002, nov). Renewable energy from the ocean. Marine Policy 26(6), 471-479.

Sagar, A. \& B. Van Der Zwaan (2006). Technological innovation in the energy sector: R\&D, deployment and learningby-doing. Energy Polivy 34(17), 2601-2608. 